\title{
Homophonic and semantic priming of Japanese kanji words: A time course study
}

\author{
Hsin-Chin Chen and Takashi Yamauchi \\ Texas A\&M University, College Station, Texas \\ Katsuo TAMAOKa \\ Hiroshima University, Hiroshima, Japan \\ AND \\ JyOTSNA VAID \\ Texas A\&M University, College Station, Texas
}

\begin{abstract}
In an examination of the time course of activation of phonological and semantic information in processing kanji script, two lexical decision experiments were conducted with native readers of Japanese. Kanji targets were preceded at short $(85-\mathrm{msec})$ and long $(150-\mathrm{msec})$ intervals by homophonic, semantically related, or unrelated primes presented in kanji (Experiment 1) or by hiragana transcriptions of the kanji primes (Experiment 2). When primes were in kanji, semantic relatedness facilitated kanji target recognition at both intervals but homophonic relatedness did not. When primes were in hiragana, kanji target recognition was facilitated by homophonic relatedness at both intervals and by semantic relatedness only at the longer interval. The absence of homophonic priming of kanji targets by kanji primes challenges the universal phonology principle's claim that phonology is central to accessing meaning from print. The stimuli used in the present study may be downloaded from www.psychonomic.org/archive.
\end{abstract}

The role of phonology in how readers access meaning from print has been hotly debated. At issue is whether accessing the semantic representation of a word requires prior activation of the word's pronunciation, as the universal phonology principle claims (Perfetti, Zhang, \& Berent, 1992), or whether, as the dual route model of reading comprehension claims, access to meaning proceeds via a dominant direct orthographic route and a slower indirect phonological route (see, e.g., Coltheart, 2000; Coltheart, Rastle, Perry, Langdon, \& Ziegler, 2001; Seidenberg, 1985). ${ }^{1}$ Although substantial research has been conducted on this issue, much of it has involved readers of alphabetic scripts (English, in particular), in which there is a close correspondence between phonology and orthography, making the relative contribution of the two components hard to disentangle.

A better test of whether or not phonology is activated in word recognition prior to access to meaning is provided by readers of logographic writing systems, such as Chinese, since in these systems phonology and orthography do not overlap and readers cannot use orthography-to-phonology conversion rules. If activation of phonology were shown to be a central component of word identification for logographic readers, the universal phonology principle would have more force.

Several word recognition studies with Chinese readers have appeared in recent years. Perfetti and colleagues (e.g., Perfetti \& Zhang, 1995) have argued that phonology is automatically activated in logographic reading and is required for access to meaning. In one often cited study, Perfetti and Tan (1998) reported an early homophonic priming effect for Chinese, at a 57-msec stimulus onset asynchrony (SOA). However, in this study (see also Tan \& Perfetti, 1997) a naming task was used in which articulatory demands could well have contributed to the phonological effects observed. A similar interpretive problem arises with the Stroop test used by Spinks, Liu, Perfetti, and Tan (2000), in which phonological activation was also observed. Indeed, studies with Chinese readers in which phonological priming in a naming task was directly compared with that in a task that can be performed without articulation, such as a lexical decision task, report priming effects mainly for naming (Shen \& Forster, 1999). Furthermore, even in studies of naming, evidence for phonological priming is not consistently obtained in logographic readers. For example, Perfetti and Tan's finding was not replicated by other researchers (Chen \& Shu, 2001; Wu \& Chen, 2000; Wu \& Chou, 2000). Thus, it would appear that the evidence from Chinese readers to date does not provide a clear test of the universal phonology principle.

Such a test would require a demonstration of phonological priming on a task that could arguably be performed without phonological processing and a demonstration that phonological priming precedes semantic priming. Both

H.-C.Chen, hc_chen@neo.tamu.edu 
of these elements were incorporated into the design of the present study, which was conducted with native readers of Japanese kanji (a logographic script derived from Chinese). In this study, we used a primed lexical decision paradigm with kanji targets to examine whether or not homophonic priming occurs earlier than semantic priming of kanji. Before we turn to the study, consideration of the relevant properties of kanji and of previous studies of kanji processing may be useful.

\section{Previous Studies of Word Recognition in Kanji}

With respect to phonological and semantic processing, kanji is like Chinese but is also different in some ways. Like Chinese, kanji characters are not phonemically decomposable; that is, components of a character do not correspond to phonemes in the pronunciation of the character. Whereas some compound kanji characters have phonetic radicals that cue the pronunciation of the character, the radicals themselves have their own meanings and pronunciations; thus, they are not really comparable to sublexical components in alphabetic scripts. However, there are many more homophones in kanji than in Chinese. Furthermore, a typical kanji character often has more than one possible pronunciation: a Kun reading (of Japanese origin) and several On readings (of Chinese origin). On readings are generally assigned to kanji words of two or more characters; the appropriate On reading is often determined by the intraword context - that is, by the other character with which a particular kanji character combines to form the word. Finally, whereas kanji characters in Japanese text represent nouns and the roots of verbs and adjectives, grammatical morphemes and function words are represented in a highly transparent, syllabic writing system (hiragana). Neuropsychological and psycholinguistic studies suggest that kana and kanji are organized and processed differently (see Shafiullah \& Monsell, 1999; Shimamura, 1987).

Three kinds of word recognition studies with kanji bear on the issue of the role of phonology in access to meaning from print. Some authors have reported phonological consistency effects with a naming task (Fushimi, Ijuin, Patterson, \& Tatsumi, 1999; Wydell, 1998): Naming is faster when the pronunciation of the phonemic radical in a kanji character matches that of the whole character (Masuda \& Saito, 2002). However, these studies leave open the question of whether or not the phonological effects observed were presemantic. Moreover, evidence for phonological effects in naming simply shows that phonology can be activated on a task that has articulation demands; it does not speak to whether or not phonology is typically activated even when the task can be performed without articulation.

Two studies involving a semantic category judgment task with homophonic foils do speak to this issue. Wydell, Patterson, and Humphreys (1993) and Sakuma, Sasanuma, Tatsumi, and Masaki (1998) reported that homophonic foils of correct category members (e.g., meet following the category a type offood) interfered with category exemplar judgments. However, the interference effect occurred only when the homophonic foils were also orthographically similar to their correct exemplars; furthermore, foils that were only orthographically similar also disrupted semantic category judgments. These findings suggest that although phonology contributes to the activation of kanji meaning, its contribution is evident only under certain orthographic conditions. In short, phonological similarity per se did not interfere with kanji semantic category judgments.

In a third type of study of kanji recognition, samedifferent judgments based on semantic versus phonological criteria have been examined for words presented at short or long SOAs. Morita and Matsuda (2000) reported that homophones interfered with synonym judgments and that synonyms in turn interfered with judgments of homophony. Both kinds of interference were evident at the shortest tested SOA $(140 \mathrm{msec})$. However, homophonic interference was smaller than semantic interference, and fewer participants (11\%) reported being aware of the influence of homophony on semantic judgments than vice versa $(96 \%)$. Since homophonic and semantic interference both occurred by the shortest tested interval, one does not know whether homophone activation would have preceded semantic activation at a still earlier time point.

\section{The Present Study}

From the studies outlined above, we see that phonology may be activated when kanji is accessed under certain conditions, but the strength and temporal onset of phonological activation relative to those of semantic activation are unclear. To examine these issues, in the present study we used a primed lexical decision paradigm. Targets were two-character kanji words. Primes, presented at short (85$\mathrm{msec})$ and long (150-msec) SOA intervals, were similar in meaning or sound to the targets or were unrelated in both respects. The primes were presented either in the form of two-character kanji (Experiment 1) or as hiragana homophones of the kanji primes (Experiment 2).

We hypothesized that if there is early, sustained activation of phonology in kanji word recognition, and if this contributes to meaning identification, then homophonic priming of kanji targets should be found at a shorter SOA than semantic priming whether the prime is presented in kanji (Experiment 1) or in hiragana (Experiment 2). Alternatively, if access to meaning for kanji words relies primarily on a direct orthographic route, without phonological activation, then homophonic priming should not be obtained for kanji lexical decision, whereas semantic priming should occur at the shorter SOA with kanji primes (Experiment 1) and at a delay with hiragana transcriptions of the kanji primes (Experiment 2).

\section{EXPERIMENT 1 Lexical Decision Priming of Kanji Targets by Kanji Primes}

\section{Method}

Participants. Twenty-four college students from Hiroshima University in Japan participated in the experiment. All were fluent readers of Japanese with normal or corrected-to-normal vision.

Design and Materials. The experimental design was a 2 (SOA: 85 vs. $150 \mathrm{msec}) \times 3$ (prime type: homophonic vs. semantically related vs. unrelated control) within-subjects factorial design. 
In the present study, we applied the corpus produced by Amano and Kondo (2000). This database was sampled from the Japanese newspaper Asahi Shimbun from 1985 to 1998. The corpus contains a total of 341,771 words having a total frequency of occurrence of $287,792,797$. The main target stimuli consisted of 72 two-character Japanese kanji words with an average frequency of 15.95 per million (Amano \& Kondo, 2000) and an average of 18.54 strokes. Each kanji target word (e.g., 展示, /tenji/, display) was paired with three types of two-character kanji primes: homophonic (e.g., 点字, /tenji/, Braille), semantically related (e.g., 陳列, /chinretsu/, display), and semantically and phonologically unrelated (e.g., 流浪, /ruro/, wandering) to the target word. The three prime types were carefully matched in number of strokes and mean frequency (see Table 1). Importantly, the primes bore no systematic orthographic relation to the targets. The same set of 72 main targets was presented to all the participants. However, each of the six prime conditions ( 2 SOAs $\times 3$ prime types) was paired with each main target across six groups of 4 participants each, with any given participant seeing only one prime condition for each main target. The stimuli may be downloaded from www .psychonomic.org/archive.

In addition, 24 filler kanji pairs with primes that were unrelated to targets were intermixed with the experimental trials. Ninetysix pseudowords (e.g., 付豆, /futo/) were constituted by combining two existing kanji characters that are not normally paired with one another. Each pseudoword target was also paired with a real twocharacter kanji prime.

Each participant received a different randomized sequence from one of six counterbalanced lists ( 2 SOAs $\times 3$ prime types). Each list consisted of 192 trials containing 72 main prime-target word pairs (i.e., 24 homophonic, 24 semantically related, and 24 unrelated control pairs), 24 filler word pairs, and 96 nonword pairs; half of each type of prime-target pairs were presented at the $85-\mathrm{msec}$ SOA, and half were presented at the 150-msec SOA.

Procedure. The participants, tested individually, were first shown a fixation stimulus (cross) for 1,000 msec, followed by a kanji prime shown at the center of the screen at an SOA of either 85 or $150 \mathrm{msec}$. Following the prime presentation, a kanji target appeared at the center of the screen until the participant's speeded lexical decision response. Reaction time (RT) was recorded from the onset of target presentation until the participant pressed a button. The participants received 10 practice trials at the beginning of the experiment. A rest was given after every 48 trials. The experiment was administered on personal computers using the E-Prime software package (Schneider, Eschman, \& Zuccolotto, 2002).

\section{Results and Discussion}

All RT analyses were carried out with correct responses only. For each participant and in each condition, trials with RTs shorter than $200 \mathrm{msec}$ or more than 2 SDs above the mean were discarded. This procedure resulted in the rejection of $5 \%$ of the observations. ${ }^{2}$ Both subject-based $\left(F_{1}\right)$ and item-based $\left(F_{2}\right)$ two-way $(\mathrm{SOA} \times$ prime type $)$ ANOVAs were conducted. Although our analyses focused on the RT data with outliers removed, the accuracy data,

Table 1

Mean Number of Strokes and Mean Frequency of Kanji Primes Used in Experiment 1

\begin{tabular}{lccc}
\hline \multicolumn{3}{c}{ of Kanji Primes Used in Experiment 1 } \\
\cline { 2 - 4 } & Semantic & Prime Type & Comophone \\
\hline Mean strokes & 18.75 & 18.79 & 18.79 \\
Mean frequency & 12.53 & 12.44 & 12.52 \\
\hline
\end{tabular}

Note-The frequency counts were based on Amano and Kondo's (2000) report of number of appearances per million words. calculated from the entire set of trials, are also reported (see Table 2).

Overall, no homophone priming effect was observed, but semantic priming occurred as indicated in the significant main effects of prime type for RT $\left[F_{1}(2,46)=\right.$ $\left.4.40, p<.05 ; F_{2}(2,142)=4.14, p<.05\right]$ and accuracy $\left[F_{1}(2,46)=3.55, p<.05 ; F_{2}(2,142)=3.77, p<.05\right]$. Furthermore, there was a main effect of SOA on RT $\left[F_{1}(1,23)=7.51, p<.01 ; F_{2}(1,71)=6.45, p<.05\right]$ but not on accuracy $\left[F_{1}(1,23)<1 ; F_{2}(1,71)=1.25, p=.27\right]$. No interaction was found in either the RT or the accuracy analysis $(F \mathrm{~s}<1)$.

Our interest in the time course of the priming effects led us to do further analyses, ${ }^{3}$ which showed that the semantic priming effect was significant at the long SOA [for RT, $t D N_{1}(92)=2.03, p<.05 ; t D N_{2}(284)=1.82, p=.05$; for accuracy, $t D N_{1}(92)=1.90, p=.05 ; t D N_{2}(284)=1.99$, $p<.05$ ] and marginally significant at the short SOA [for RT, $t D N_{1}(92)=1.87, p=.05 ; t D N_{2}(284)=1.38, p=$ .08 ; for accuracy, $t D N_{1}(92)=1.59, p=.07 ; t D N_{2}(284)=$ $1.66, p=.07]$. For homophonic primes, however, the priming effect was absent at both SOAs in all analyses $(t D N s<1)$, except for a marginally significant effect in the accuracy data at the short SOA $\left[t D N_{1}(92)=1.59, p=\right.$ $\left..07 ; t D N_{2}(284)=1.66, p=.07\right]$.

Overall, our findings indicate that kanji lexical decision was facilitated by semantic priming starting at the short SOA tested $(85 \mathrm{msec})$, whereas homophonic relatedness of kanji primes to targets did not facilitate kanji recognition at either SOA tested, suggesting that phonological activation of kanji is weaker than semantic activation.

Is it possible that homophonic priming is absent in our study because phonology was activated early but dissipated before $85 \mathrm{msec}$ ? If this were the case, one should not find phonological priming in other studies with logographic readers at SOAs beyond $85 \mathrm{msec}$. However, studies with Chinese readers that have claimed that phonology is activated report that phonology is sustained long enough to produce priming at SOAs well beyond the $85 \mathrm{msec}$ that we used. For example, Perfetti and Tan (1998) reported homophonic priming effects present at SOAs of up to $115 \mathrm{msec}$, Tan and Perfetti (1997) reported phonologically mediated semantic priming effects persisting up to a 243-msec SOA, and Perfetti and Zhang (1995) reported phonological interference effects on a synonym judgment task at SOAs of up to $310 \mathrm{msec}$.

Although it appears unlikely that our failure to find homophonic priming effects at the $85-\mathrm{msec}$ SOA was due to both an early activation and an early dissipation of phonology, our second experiment addressed this possibility. In Experiment 2, hiragana transcriptions of the homophonic, semantic, and unrelated primes from Experiment 1 were used as primes. Thus, exactly the same phonological information was presented as in Experiment 1 but in a script that favors phonological processing (Forster \& Yoshimura, 1994; Yamada, 1998). If phonology is indeed activated early but fades quickly, in Experiment 2 we should not find the homophone priming that we found in Experiment 1 . However, if there is early and sustained phonolog- 
Table 2

Mean Reaction Time (RT, in Milliseconds) and Accuracy (\%) (With Standard Errors) of Kanji Word Recognition As a Function of Kanji Versus Hiragana Primes (Experiments 1 and 2, Respectively)

\begin{tabular}{|c|c|c|c|c|c|c|c|c|}
\hline \multirow[b]{4}{*}{ Prime Type } & \multicolumn{8}{|c|}{$\mathrm{SOA}$} \\
\hline & \multicolumn{4}{|c|}{$85 \mathrm{msec}$} & \multicolumn{4}{|c|}{$150 \mathrm{msec}$} \\
\hline & \multicolumn{2}{|c|}{ RT } & \multicolumn{2}{|c|}{$\%$} & \multicolumn{2}{|c|}{ RT } & \multicolumn{2}{|c|}{$\%$} \\
\hline & M & $S E$ & $M$ & $S E$ & $M$ & $S E$ & $M$ & $S E$ \\
\hline \multicolumn{9}{|c|}{ Kanji (Experiment 1) } \\
\hline Semantic & 741 & 16.0 & 92.7 & 1.8 & 726 & 22.6 & 94.8 & 2.1 \\
\hline Homophone & 780 & 20.4 & 92.7 & 2.0 & 753 & 22.2 & 92.7 & 1.8 \\
\hline Unrelated & 775 & 20.2 & 89.2 & 1.8 & 762 & 23.9 & 90.6 & 1.5 \\
\hline \multicolumn{9}{|c|}{ Hiragana (Experiment 2) } \\
\hline Semantic & 800 & 35.3 & 90.6 & 1.5 & 771 & 25.6 & 93.8 & 1.4 \\
\hline Homophone & 706 & 19.5 & 95.5 & 1.3 & 701 & 24.2 & 94.1 & 1.8 \\
\hline Unrelated & 793 & 27.4 & 90.3 & 2.1 & 798 & 28.6 & 89.6 & 2.0 \\
\hline
\end{tabular}

ical activation induced by the transparency of the hiragana script, hiragana homophone primes should facilitate the subsequent lexical decision about kanji target words. The relative unfamiliarity of the primes (due to their being hiragana transcriptions of words normally written in kanji) might slow their processing, but semantic priming was still expected, particularly at the longer SOA.

\section{EXPERIMENT 2 \\ Lexical Decision Priming of Kanji Targets by Hiragana Primes}

\begin{abstract}
Method
Participants. A new group of 24 college students from Hiroshima University participated in this experiment. All were fluent readers of Japanese with normal or corrected-to-normal vision.

Design and Stimuli. The design and stimuli were identical to those described for Experiment 1 except that all the primes were presented in hiragana script.

Apparatus and Procedure. The apparatus and procedure in Experiment 2 were the same as in Experiment 1.
\end{abstract}

\section{Results and Discussion}

The same criteria and analyses as in Experiment 1 were applied to the present experiment. The cutoffs for extreme RT scores led to the rejection of $5 \%$ of the observations (see note 2 ).

Overall, as was expected, phonological priming was more evident than semantic priming. A significant effect of prime type was found [for RT, $F_{1}(2,46)=16.88, p<$ $.001 ; F_{2}(2,142)=8.24, p<.001$; for accuracy, $F_{1}(2,46)=$ $\left.5.68, p<.01 ; F_{2}(2,142)=4.81, p<.05\right]$. There was no effect of SOA $(F \mathrm{~S}<1)$ for any of the analyses, nor were there any significant interactions between prime type and SOA [all $F \mathrm{~s}<1.48, p>.24$ ]. Further analyses revealed that at the $85-\mathrm{msec} \mathrm{SOA}$, the homophonic priming effect was significant in the subject-based RT analysis $\left[t D N_{1}(92)=4.21, p<.001\right]$ and marginally significant in the item-based RT analysis $\left[t D N_{2}(284)=1.77, p=.06\right]$ [for accuracy, $t D N_{1}(92)=2.57, p<.05 ; t D N_{2}(284)=$ $2.44, p<.05]$. At the 150 -msec SOA, the homophonic priming effect was also significant [for RT, $t D N_{1}(92)=$
$4.75, p<.001 ; t D N_{2}(284)=2.79, p<.01$; for accuracy, $\left.t D N_{1}(92)=2.23, p<.05 ; t D N_{2}(284)=2.11, p<.05\right]$.

Furthermore, as we expected, there was no semantic priming effect at the $85-\mathrm{msec}$ SOA in either the RT or the accuracy analysis $(t D N \mathrm{~s}<1)$. The semantic priming effect was marginally significant for RT at the $150-\mathrm{msec}$ $\mathrm{SOA}\left[t D N_{1}(92)=1.31, p=.09 ; t D N_{2}(284)=1.47, p=\right.$ $.08]$ and was significant for accuracy $\left[t D N_{1}(92)=2.06\right.$, $\left.p<.05, t D N_{2}(284)=1.95, p<.05\right]$.

Our results show that kanji targets can benefit from homophonic hiragana primes at SOAs as short as $85 \mathrm{msec}$. With respect to semantic priming, our results showed that hiragana primes weakly facilitated kanji target recognition and did so only at the longer SOA.

\section{GENERAL DISCUSSION}

In this study, we sought to test the universal phonology principle, according to which access to meaning from print requires the activation of phonological information, even in readers of logographic scripts. Unlike some previous studies with Chinese readers (e.g., Perfetti \& Tan, 1998) in which the argument was made that, once derived, phonology is sustained long enough to produce priming at intervals beyond those used in the present study, we found no evidence for homophonic priming of kanji lexical decision from kanji primes. The lack of a homophonic priming effect leads us to conclude that phonology is not central for kanji processing. Instead, our results showed fast and robust semantic priming of kanji targets by kanji primes.

We believe that our study provided a better test of the claim that phonology is central and activated prior to meaning in word recognition than previous attempts, and that our failure to find support for the claim thus presents a challenge to the universal phonology view. Furthermore, our results accord with findings from time course studies of phonological and semantic priming in Chinese readers (Chen \& Shu, 2001; Wu \& Chen, 2000; Wu \& Chou, $2000)$ that failed to replicate the early homophonic priming effect reported by Perfetti and Tan (1998) even when using the same stimuli as in the latter study (see Chen 
\& Shu, 2001). These studies instead report that semantic priming occurred consistently and much earlier than phonological priming in Chinese readers. Taken together, these results support the notion that readers of logographic scripts rely on a direct orthographic route when accessing meaning from print.

In our second experiment, in which hiragana primes were presented with kanji targets (Experiment 2), we found early and robust phonological priming and weaker and delayed semantic priming. This diverging pattern of priming as a function of prime script type was directly confirmed in an analysis in which the data were pooled across experiments. When experiment was included as a factor, there was a significant prime type $\times$ experiment interaction in $\mathrm{RT}\left[F_{1}(2,92)=15.30, p<.001 ; F_{2}(2,142)=\right.$ $10.23, p<.001]$. If phonology does not play a major role in kanji processing, how may one interpret the nature of this phonological effect in Experiment 2, in which the targets were also written in kanji?

As transcriptions of kanji primes, our hiragana primes were somewhat novel stimuli, and it is not immediately obvious how they might be processed. From other studies with hiragana, we know that hiragana words are processed differently from kanji words in terms of phonological activation (e.g., Forster \& Yoshimura, 1994). Since the hiragana primes in our study were actually derived from kanji words and thus did not have a familiar lexical entry in the hiragana orthographic lexicon, their phonology must have been generated through a nonlexical (assembly) route. Once generated, this phonological information could have facilitated activation of the stored pronunciation of the kanji target word in the kanji phonological lexicon and, from there, the semantic representation of the kanji targets could have been accessed. ${ }^{4}$ As Coltheart (personal communication, January 12, 2006) noted, this pathway is comparable to that which an English reader would use to decide if the pseudohomophone kote sounds like the name of a type of garment. At short SOAs, there should be sufficient time to activate the phonology of the hiragana primes and retrieve the stored pronunciation of the kanji target postlexically, but not enough time to get to the semantic representation. This account could explain why, in our Experiment 2, homophone priming was observed as early as the 85 -msec SOA but semantic priming emerged only at the longer SOA.

In a sense, the hiragana transcriptions in our Experiment 2 also served as a kind of repetition prime (a possibility suggested to us by Steve Lupker). As in cross-modal repetition priming, in which the phonology of an auditory stimulus facilitates processing of its visual counterpart, presenting kanji primes in hiragana transcription may have facilitated homophonic processing of the kanji targets.

Whatever the means by which the hiragana primes activated the phonology of the kanji targets, our results show that kanji phonology could not efficiently be recruited to help the processing of semantic information of the kanji words. If phonology is indeed useful in accessing semantic information, as the universal phonology principle claims, how could phonology be strongly activated from $85 \mathrm{msec}$ onward but still have difficulty reaching the meaning of its kanji target? The answer would seem to be that phonological activation is not central in kanji processing.

\section{AUTHOR NOTE}

A preliminary report of this research was presented at the annual meeting of the American Psychological Society, Los Angeles, 2005. Correspondence concerning this article should be addressed to H.-C. Chen, Department of Psychology, Texas A\&M University, College Station, TX 77843-4235 (e-mail: hc_chen@neo.tamu.edu).

\section{REFERENCES}

Amano, S., \& Kondo, T. (2000). Nihongo-no goi-tokusei [Lexical properties of Japanese] (Vol. 7). Tokyo: Sanseido.

Chen, H.-C., \& ShU, H. (2001). Lexical activation during the recognition of Chinese characters: Evidence against early phonological activation. Psychonomic Bulletin \& Review, 8, 511-518.

Coltheart, M. (2000). Commentary on Section 3. Dual routes from print to speech and dual routes from print to meaning: Some theoretical issues. In A. Kennedy, R. Radach, D. Heller, \& J. Pynte (Eds.), Reading as a perceptual process (pp. 475-490). Amsterdam: Elsevier.

Coltheart, M., Rastle, K., Perry, C., Langdon, R., \& Ziegler, J. (2001). DRC: A dual route cascaded model of visual word recognition and reading aloud. Psychological Review, 108, 204-256.

Forster, K., \& Yoshimura, K. (1994, December). Phonological processes in visual word recognition: Masked priming experiments in Japanese and Chinese. Paper presented at the Asian-Australian Workshop on Cognitive Processing of Asian Languages, Sydney.

Fushimi, T., Ijuin, M., Patterson, K., \& Tatsumi, I. F. (1999). Consistency, frequency, and lexicality effects in naming Japanese kanji. Journal of Experimental Psychology: Human Perception \& Performance, 25, 382-407.

KIRK, R. E. (1995). Experimental design: Procedures for the behavioral sciences (3rd ed.). Belmont, CA: Brooks/Cole.

Masuda, H., \& SAITO, H. (2002). Interactive processing of phonological information in reading Japanese kanji character words and their phonemic radicals. Brain \& Language, 81, 445-453.

Morita, A., \& Matsuda, F. (2000). Phonological and semantic activation in reading two-kanji compound words. Applied Psycholinguistics, 21, 487-503.

Perfetti, C. A., \& Tan, L. H. (1998). The time course of graphic, phonological, and semantic activation in Chinese character identification. Journal of Experimental Psychology: Learning, Memory, \& Cognition, 24, 101-118.

Perfetti, C. A., \& Zhang, S. (1995). Very early phonological activation in Chinese reading. Journal of Experimental Psychology: Learning, Memory, \& Cognition, 21, 24-33.

Perfetti, C. A., Zhang, S., \& Berent, I. (1992). Reading in English and Chinese: Evidence for a "universal" phonological principle. In R. Frost \& L. Katz (Eds.), Orthography, phonology, morphology, and meaning (Advances in Psychology, Vol. 94, pp. 227-248). Amsterdam: Elsevier, North-Holland.

Sakuma, N., Sasanuma, S., Tatsumi, I. F., \& Masaki, S. (1998). Orthography and phonology in reading Japanese kanji words: Evidence from the semantic decision task with homophones. Memory \& Cognition, 26, 75-87.

Schneider, W., Eschman, A., \& Zuccolotto, A. (2002). E-Prime user's guide. Pittsburgh: Psychology Software Tools.

SEIDENBERG, M. S. (1985). The time course of phonological code activation in two writing systems. Cognition, 19, 1-30.

Shafiullah, M., \& Monsell, S. (1999). The cost of switching between kanji and kana while reading Japanese. Language \& Cognitive Processes, 14, 567-607.

Shen, D., \& Forster, K. I. (1999). Masked phonological priming in reading Chinese words depends on the task. Language \& Cognitive Processes, 14, 429-459.

Shimamura, A. P. (1987). Word comprehension and naming: An analysis of English and Japanese orthographies. American Journal of Psychology, 100, 15-40.

Spinks, J. A., Liu, Y., Perfetti, C. A., \& Tan, L. H. (2000). Reading Chinese characters for meaning: The role of phonological information. Cognition, 76, B1-B11. 
TAn, L. H., \& Perfetti, C. A. (1997). Visual Chinese character recognition: Does phonological information mediate access to meaning? Journal of Memory \& Language, 37, 41-57.

WU, J.-T., \& CHEN, H.-C. (2000). Evaluating semantic priming and homophonic priming in recognition and naming of Chinese characters. Chinese Journal of Psychology, 42, 65-86.

Wu, J.-T., \& CHOU, T. L. (2000). The comparison of relative effects of semantic, homophonic, and graphic priming on Chinese character recognition and naming. Acta Psychologica Sinica, 32(Suppl.), 34-41.

WyDELL, T. N. (1998). What matters in kanji word naming: Consistency, regularity or On/Kun-reading difference? Reading \& Writing: An Interdisciplinary Journal, 10, 359-373.

Wydell, T. N., Patterson, K. E., \& Humphreys, G. W. (1993). Phonologically mediated access to meaning for kanji: Is a rows still a rose in Japanese kanji? Journal of Experimental Psychology: Learning, Memory, \& Cognition, 19, 491-514.

YAMADA, J. (1998). The time course of semantic and phonological access in naming kanji and kana words. Reading \& Writing, 10, 425-437.

\section{NOTES}

1. The dual route model for accessing meaning from print (termed $D R-M$ by Coltheart, 2000) is to be distinguished from the dual route model for generating phonology from print (termed $D R-P$; Coltheart, 2000). The latter consists of a lexical mechanism that retrieves a stored phonological representation of a word directly through a lexical entry and an assembly mechanism that assembles the output of grapheme to phoneme conversion rules.

2. We also conducted the same analyses with different cutoff points (e.g., $2.5 S D, 1,500 \mathrm{msec}$ ). The basic results with these cutoff points were analogous to those described in the two experiments.

3 . The analyses of comparisons within the simple main effects followed Kirk (1995, pp. 134-137, 282-286, 454-472).
4. As one reviewer suggested, some of our homophonic primes in Experiment 2 may have had more than one meaning. A semantic priming effect could have been diluted by this semantic ambiguity. To test for this possibility, we analyzed RT scores by stimulus ambiguity, comparing responses to ambiguous items $(n=35)$ to responses to nonambiguous items $(n=37)$, but found no effect of ambiguity $[F(1,70)<1]$ and no interaction with any of the other variables (all $p \mathrm{~s}>.1$ ).

\section{ARCHIVED MATERIALS}

The following materials associated with this article may be accessed through the Psychonomic Society's Norms, Stimuli, and Data archive, www.psychonomic.org/archive.

To access these files, search the archive for this article using the journal (Psychonomic Bulletin \& Review), the first author's name (Chen), and the publication year (2007).

FILE: Chen-PBR-2007.zip

DESCRIPTION: The compressed archive file contains three files:

Chen-PBR-InPress.xls, containing stimuli, strokes, and frequencies used in Chen, Yamauchi, Tamaoka, and Vaid (2007) as a 30K Excel worksheet generated by Excel 2000 for PC.

Chen-PBR-2007.txt, containing the same materials as above, as a $6 \mathrm{~K}$ tab-delimited text file generated by Excel 2000 for PC.

Chen-PBR-2007.pdf, containing the same materials as above, as a $360 \mathrm{~K}$ pdf file generated by Adobe Acrobat 5.0 for PC. This file can be read using Adobe Reader without installing special Asian fonts.

AUTHOR's E-MAIL ADDRESS: hc_chen@neo.tamu.edu.

AUTHOR's WeB SITE: http://people.tamu.edu/ hc_chen.

(Manuscript received February 27, 2005; revision accepted for publication June 8, 2006.) 